advantageous to have one of the cross lines made shorter than the width of the spectrum. The disc is then so placed in the instrument that this short line is vertical, and hence parallel with the spectrum lines. Under such circumstances, when this short vertical cross line is placed over a bright spectrum line, the latter is seen extending above and below it, and the small dark ends of the cross line being thus brought prominently in view, materially assist in marking the spectrum line upon which they are placed. The horizontal arms of the cross are, in this case, of no particular advantage in marking the spectrum lines, but they facilitate the finding of the optic axis of the telescope, and, where the instrument is provided with an illuminated scale, help to align the same. It is best to so place the scale that one end of the short vertical line reaches about the middle thereof.

Various devices may be employed to fix the disc in the spectroscope. If the instrument is provided with a negative ocular, the disc may be placed against the diaphragm, and held in position by a spring wire. It is well in that case to provide the ocular with a sliding eye lens, which can be cheaply done by any good brass worker. If the instrument has a positive ocular and a diaphragm in it, or in the telescope tube, the disc may, as before, be laid against the diaphragm, and if such is in the telescope tube, focused by sliding the ocular, or if that be fixed, the diaphragm may be moved till the cross lines are in focus. Where there is a positive ocular and no diaphragm, as is the case with some instruments, the disc may be cemented to a brass ring of proper diameter to fit snugly inside the telescope tube, and the proper position having been found, the ring can be so set that the cross lines will be at that point. Each of the above devices has been tried in this laboratory and found satisfactory, and others will probably suggest themselves.

It is true that such devices do not always succeed in making the center of the cross and the axis of the telescope coincide; but this is the case in but few cross wire spectroscopes, and, for that matter, a spectroscope is not a transit, and does not require such a rigid adjustment of the line of collimation as the latter instrument. If the center of the cross is at the center of the disc, and the disc fits its tube snugly, the cross lines will be sufficiently centered. Were an absolutely accurate adjustment of the line of collimation worth the cost, it could be secured by inserting an adjustable ring at the proper focal point and attaching the disc thereto.

The same method of supplying cross lines answers equally well for microscopical observations, either for goniometric, or for polariscopic work; in fact, it was from noting its utility in such microscopic work, that the idea arose of applying it to the spectroscopic investigations.

Several of the above-described discs have been made for this laboratory by the Bausch \& Lomb Optical Co. and they have given perfect satisfaction.

C. M. Clark

\section{NOTE ON SOME PENNSYLVANIA FISHES}

DuRING the warm weather of 1908 and 1909 Mr. R. W. Wehrle, of Indiana, Indiana County, Pa., made a number of collections of fishes, amphibians and reptiles, from his vicinity. As almost all animal life is either extinct or rapidly becoming so in the main basin of the Conemaugh River, possibly the following list will be of use in partly recording a vanishing fish fauna. I take this opportunity to thank Mr. Wehrle for his care in collecting full series of specimens, besides notes and information relative to the former condition of the fish fauna. Notropis photogenis and Micropterus dolomieu are from Cherry Run and all the others are from Two Licks Creek, besides such other streams as may be mentioned after each. Ichthyomyzon concolor, Salvelinus fontinalis, Campostoma anomalum, also from Ramsey's Run; Pimephales notatus, Ramsey's Run, Harris's Run, Cherry Run and Marsh Run; Semotilus atromaculatus, Ramsey's, Harris's, Cherry and Marsh Runs; Leuciscus elongatus, Ramsey's and Harris's Runs; Notropis cornutus, Ramsey's and Cherry Runs; N. atherinoides, Cherry Run; Ericymba buccata, Cherry and Ram- 
sey's Runs; Rhinichthys atronasus, Ramsey's and Marsh Runs; Hybopsis kentuckiensis, Catostomus commersonnii, Ramsey's and Cherry Runs; C. nigricans, Moxostoma aureolum, Cherry Run; Ameiurus nebulosus, Noturus flavus, Ambloplites rupestris, Ramsey's Run; Hadropterus macrocephalus, Boleosoma nigrum, Cherry and Marsh Runs; Etheostoma flabellare, Marsh Run; Cottus gracilis, Ramsey's Run.

On July 23, 1899, I secured an example of Leuciscus margarita in a tributary of the Alleghany River near Cole Grove, McKean County, the first I know of from that basin.

On July 1, 1907, Mr. T. D. Keim and myself took two examples of Notropis boops Gilbert from the Alleghany just above Foxburg, in Clarion County, also the first from that river.

I may note that Coccogenia Cockerell and Callaway, Proc. Biol. Soc. Wash., XXII., 1909 , p. 190 , is an exact synonym of Coccotis Jordan, Rep. Geol. Surv. Ohio, IV., 1882, p. 852, type Hypsilepis coccogenis Cope, monotypic.

Henry W. Fowler

Academy of Natural Sciences, Philadelphia

\section{SCIENTIFIC BOOKS}

Die Geographische Verbreitung der Schmetterlinge. Dr. Arnold Pagenstecher. Mit zwei Karten. 8vo, pp. ix +451 . Verlag von Gustav Fischer in Jena. 1909.

Geheimrat Dr. Arnold Pagenstecher has long been favorably known to students of oriental lepidoptera as the author of a number of faunal and monographic papers of the highest merit. His investigations, which have chiefly related to the Malay Archipelago, inevitably led him to the consideration of questions of geographical distribution, and as the result of comprehensive studies we have before us the present volume.

The work divides itself into three sections.

The first section, occupying fifty-nine pages, deals with the underlying causes of the geographical distribution of the lepidoptera. Soil, temperature, humidity, air-currents and vegetation are discussed with relation to the distribution of the forms of lepidopterous life. The distribution of the lepidoptera at various elevations above sea-level is considered. The migrations of butterflies, the cosmopolitan character of some species, seasonal dimorphism and local variation are touched upon. Several pages are devoted to the consideration of the influence of the glacial epoch and the various mutations which the surface of the earth has undergone in past geological ages. The influence of parasitic life upon the distribution of species concludes this portion of the work.

The second portion of the work, which occupies the body of the book, extending from page 62 to page 401 , is devoted to a statement of the results which have thus far been reached by students of the lepidoptera who have written upon the faunæ of the various continents and islands. The various published lists of species are cited and briefly analyzed, and there is thus supplied a very valuable guide to the literature of the whole subject. This portion of the work displays enormous industry on the part of the author and a very thorough familiarity with what has been written. Dr. Pagenstecher recognizes eight faunal regions, and the distribution which he accepts may be given in tabular form as follows :

I. North-Polar Region.

(The entire circumpolar northern arctic territory.)

II. Palfarctic (Eubopeo-Siberian) Region. Subregions.

1. European.

2. Mediterranean.

Including the Azores, Madeira, the Canaries and Cape Verde Islands; northern Africa, Asia Minor and Syria, as well as all parts of Europe bordering on the northern shores of the Mediterranean.

3. Siberian.

4. Manchurian.

Including Japan.

III. INDIAN REgION.

1. India to the Himalayan foot-hills.

2. Ceylonese.

Ceylon and the Maldives and Laccadives. 